\title{
Can legal frameworks for disaster response be improved?
}

\section{Dug Cubie}

Faculty of Law, UCC

... when the occasion arises, every Nation should give its aid to further the advancement of other Nations and save them from disaster and ruin, so far as it can do so without running too great a risk ... If a Nation is suffering from famine, all those who have provisions to spare should assist in its need ... To give assistance in such dire straits is so instinctive an act of humanity that hardly any civilised Nation is to be found which would refuse absolutely to do so.

Emer de Vittel, The Law of Nations (1758)

\section{Introduction}

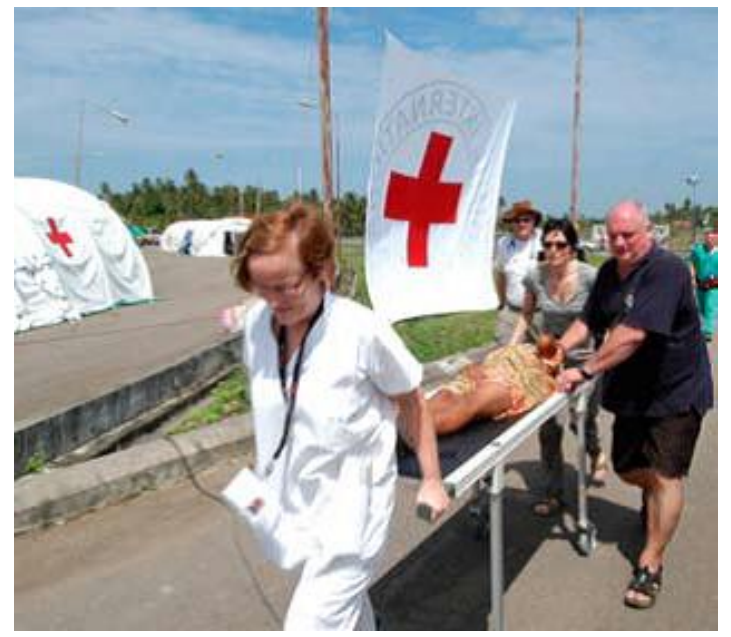

Figure 1: A woman injured in the 2004 Indian Ocean Tsunami being brought it on ICRC field hospital (ICRD: Thierry Gassmann)

We are all familiar with images of search and rescue teams, medics, and engineers arriving to help after a disaster, such as following the March 2011 Japanese earthquake and tsunami or the massive floods in Pakistan in July 2010.

In recognition of the devastating impact natural or human-made disasters can have on individuals and communities, an estimated US \$7billion was spent globally in 2008 on emergency assistance including food, shelter and medical care. The mere words "Pompeii", "Krakatoa" or "Chernobyl" conjure up scenes of death and destruction. So how can lawyers assist in disaster responses? 
Cynics may say that things always get more complicated when lawyers become involved. Rules, regulations and red tape - surely all of these legal tools only delay vital life saving assistance? Yet legal practitioners at a national and international level are increasingly aware that we have a lot to contribute to ensure that humanitarian assistance is delivered efficiently and effectively to people severely affected by natural or human-made disasters. My research examines the evolving international legal mechanisms to facilitate the delivery of humanitarian assistance following disasters. Drawing on international humanitarian, refugee and human rights law, there is increasing discussion of a "right to humanitarian assistance". Yet rights that are not enforceable are at best aspirational, so my research will determine whether such a right actually exists and what it might mean in practice.

\section{Legal frameworks to facilitate responses to disasters}

National legal rules surrounding the relaxation of import duties for relief goods or work visas for international humanitarian staff are just two examples that can have an immediate and positive impact on the actual delivery of aid to victims of disasters. Furthermore, risk reduction and prevention measures such as building codes and urban planning can ensure that the negative impacts of a disaster are diminished from the outset. For a country's national emergency response services, such preventative measures are crucial, including ensuring that legal frameworks for disaster mitigation and response are in place prior to a disaster occurring. Despite the severe nuclear emergency and extensive loss of life and damage caused by the 2011 Japanese earthquake and tsunami, the level of destruction would have been much worse if Japan had not learnt the lessons of the 1996 Kobe earthquake and developed a comprehensive disaster prevention and management regime.

On the other hand, Hurricane Katrina in the US highlighted that even advanced systems of disaster response can be overwhelmed - either by the scale of a disaster or by poor planning and implementation of the response. Therefore, there is a need for international systems to ensure that the global community of States and humanitarian agencies can respond effectively and appropriately when a Government is unable or unwilling to provide the necessary humanitarian assistance to its own citizens.

\section{International responses to disasters}

International human rights law already obliges States to protect a range of rights which are equally applicable in the event of disasters, such as the rights to life, health, and an adequate standard of living. Furthermore, the International Red Cross Movement and many other humanitarian agencies consider there is an additional right to both offer and receive 


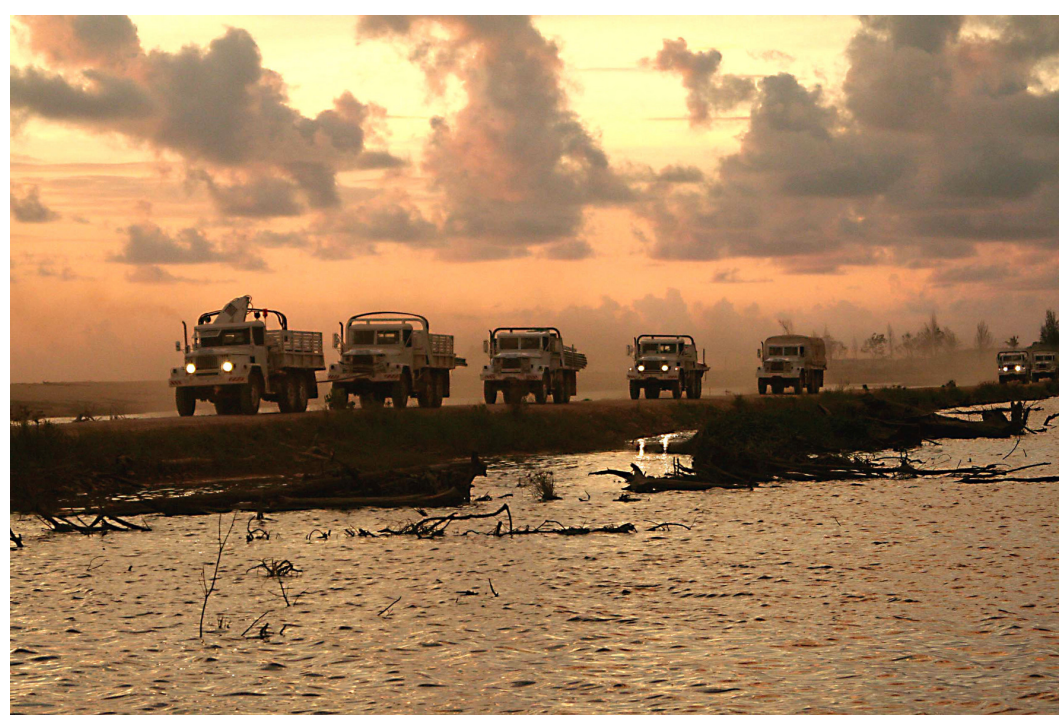

Figure 2: A fleet of Norwegian M6 trucks delivering relief supplies after the 2004 Indian Ocean Tsunami (IFRC: Raqai Yani)

humanitarian assistance. It follows that humanitarian agencies have a corresponding duty to provide support to disaster victims and those vulnerable to future disasters.

Two contrasting approaches can be taken to improve the delivery of humanitarian assistance. A technical and operational approach addresses potential barriers for delivery of aid such as import duties and visas. Alternatively, a rights-based approach focuses on the entitlement of individual victims to an acceptable level of services post-disaster and the enforceability of these rights.

The approach taken goes to the heart of the potential tension that can exist following a major natural or human-made disaster; do individual rights take precedence over State sovereignty, or does a Government have a right to assert the non-interference in the domestic affairs of a sovereign State? While this may appear to be an academic discussion, in May 2008 Cyclone Nargis killed at least 138,000 people and affected over 2.4 million in Myanmar. The ruling junta in Myanmar was extremely reluctant to allow Western aid agencies to access the victims of the cyclone, despite reports that the national response was simply unable to cope with the scale of the disaster. For the first time, some Governments raised the prospect of military intervention to provide humanitarian assistance to the victims of a natural disaster and UK, US and French warships loaded with humanitarian supplies moved into position off the coast of Myanmar. Ultimately, diplomatic and humanitarian pressure ensured that limited aid was provided to the victims without the need for military action, but this aid arrived weeks after the event and in much lower quantities than could have been provided.

In the mid-1990s, the Sudanese academic and diplomat Francis Deng advanced the concept of "sovereignty as responsibility" to highlight the duties that Governments have towards people displaced from their homes as a result of war, human rights abuses or nat- 
ural disasters. This formative development subsequently led the UN and world leaders to endorse the Responsibility to Protect doctrine in 2005, thereby establishing a global legal responsibility to ensure that war crimes, genocide, ethnic cleansing and crimes against humanity are tackled decisively. While the original concept of sovereignty as responsibility encompassed Governments' duties in a broad range of settings where human rights may be abused, legal obligations under the Responsibility to Protect doctrine only apply to specific international crimes such as war crimes and genocide. However, the delayed response to Cyclone Nargis raised an as-yet unanswered question. Should States have a similar Responsibility to Protect their citizens, and the international community a corresponding responsibility to intervene, to prevent suffering caused by natural or human-made disasters?

Moreover, it is not just in situations where a Government is unwilling to facilitate an international response that the rights and responsibilities of humanitarian actors are at issue. The 2004 Indian Ocean Tsunami affected 14 countries, as diverse as Indonesia, The Maldives and Somalia. The extent of the disaster, and the remoteness of many locations affected, severely stretched both national and international capacities to provide effective assistance to all those in need. Similarly, the Haitian earthquake of January 2010 effectively destroyed the national response capacity as up to a quarter of all State workers were killed or injured and large parts of the national infrastructure were destroyed. It was therefore unrealistic to expect the Haitian authorities to provide the extent of humanitarian assistance required without international support. Yet the deployment of the US military to support the emergency operation was controversial. As a former US colony, the arrival of US troops was criticised internally in Haiti, and countries such as Cuba and Venezuela claimed the US response was an imperialist occupation under the guise of humanitarian assistance.

\section{Future threats and debates}

With the potential for increased frequency and severity of meteorological disasters resulting from global climate change, and the expanding number and range of organisations responding to disasters, the regulation of international humanitarian assistance is increasingly receiving attention from international institutions. For example, the EU Consensus on Humanitarian Aid was adopted in December 2007, and Irish Aid's Humanitarian Relief Policy was published in May 2009. Most notably, the UN International Law Commission proposed an examination of the rights and responsibilities surrounding disasters in 2006. As a result, over the past few years, Governments have been debating the Protection of Persons in the Event of Disasters. While this process is still in the early stages, it may lead to a legally binding international convention which Governments around the world would be expected to adhere to. 
However, it is not yet clear whether binding international law is the most effective mechanism to ensure that individuals affected by disasters receive the assistance and protection they require. There already exist a range of non-legal normative standards such as the International Red Cross Movement's Code of Conduct in Disaster Relief and the Sphere Project's Humanitarian Charter and Minimum Standards in Humanitarian Response. Would non-binding minimum standards or guidelines be more flexible and appropriate in the complex aftermath of a major disaster, and would Governments be more willing to support such non-legal measures rather than being constrained by new international legal obligations?

\section{Conclusion}

My research addresses broad conceptual notions of State sovereignty and individual rights, as well as the creation and elaboration of new norms in international law, by examining the contentious fault lines that currently exist in the development of international legal frameworks for disaster response. The interplay between sovereignty and rights, technical and rights-based approaches, and binding and non-binding rules all impact on the effective delivery of humanitarian assistance. Having worked in refugee protection and humanitarian assistance for the UN, Red Cross and NGOs for more than 10 years, my research is firmly grounded in the practical application of international rules. By examining the balance required between the competing interests of affected and donor States, Governmental and non-Governmental agencies, and humanitarian workers and individuals affected, my research will put forward clear rules and principles to improve the delivery of humanitarian actions.

As the international community debates new disaster response mechanisms, there is great potential for lawyers to contribute to the protection of victims of natural and human-made disasters. However, lawyers need to make sure that our involvement in humanitarian assistance and disaster response is appropriate, and actually benefits those most affected. The spectre of increased bureaucracy and delays due to legal uncertainty or complications is not going to assist people in the aftermath of a disaster. The practical application of legal rules have shown their value in Japan, but as a rich developed nation Japan had limited need for direct international assistance. Responding to a disaster where there is limited capacity at a national level, as seen following the Haiti earthquake, requires a different level of engagement by the international community. By extension, international lawyers need to ensure that legal frameworks in place minimise any practical barriers to the delivery of humanitarian assistance; while at the same time ensuring that individual rights are upheld and providing legal clarity for the actions of State and non-State actors.

I wish to acknowledge the help and support of the staff of the Faculty of Law and especially my supervisors, Dr. Siobhán Mullally and Dr. Siobhán Wills. I would also like to thank the Faculty of Law and Comyn Kelleher Tobin Solicitors for providing funding for my PhD. 